\title{
Prolonged Slow Expiration Technique in Infants: Effects on Tidal Volume, Peak Expiratory Flow, and Expiratory Reserve Volume
}

\author{
Fernanda C Lanza PT PhD, Gustavo Wandalsen MD PhD, Ana Caroline Dela Bianca MD PhD, \\ Carolina L Cruz PT, Guy Postiaux PT, and Dirceu Solé MD PhD
}

\begin{abstract}
BACKGROUND: Prolonged slow expiration (PSE) is a physiotherapy technique often applied in infants to reduce pulmonary obstruction and clear secretions, but there have been few studies of PSE's effects on the respiratory system. OBJECTIVE: To describe PSE's effects on respiratory mechanics in infants. METHODS: We conducted a cross-sectional study with 18 infants who had histories of recurrent wheezing. The infants were sedated for lung-function testing, which was followed by PSE. The PSE consisted of 3 sequences of prolonged manual thoraco-abdominal compressions during the expiratory phase. We measured peak expiratory flow (PEF), tidal volume $\left(V_{T}\right)$, and the frequency of sighs during and immediately after PSE. We described the exhaled volume during PSE as a fraction of expiratory reserve volume (\%ERV). We quantified ERV with the raised-volume rapid-thoracic-compression technique. RESULTS: The cohort's mean age was 32.2 weeks, and they had an average of 4.8 previous wheezing episodes. During PSE there was significant $\mathrm{V}_{\mathrm{T}}$ reduction $(80 \pm 17 \mathrm{~mL}$ vs $49 \pm 11 \mathrm{~mL}, P<.001)$, no significant change in PEF $(149 \pm 32 \mathrm{~mL} / \mathrm{s}$ vs $150 \pm 32 \mathrm{~mL} / \mathrm{s}, P=.54)$, and more frequent sighs $(40 \%$ vs $5 \%, P=.03)$, compared to immediately after PSE. The exhaled volume increased in each PSE sequence $(32 \pm 18 \%$ of ERV, $41 \pm 24 \%$ of ERV, and $53 \pm 20 \%$ of ERV, $P=.03$ ). CONCLUSIONS: It was possible to confirm and quantify that PSE deflates the lung to ERV. PSE caused no changes in PEF, induced sigh breaths, and decreased $\mathbf{V}_{T}$, which is probably the main mechanical feature for mucus clearance. Key words: prolonged slow expiration technique; physiotherapy; infant; pulmonary function test; expiratory reserve volume. [Respir Care 2011;56(12):1930-1935. (0 2011 Daedalus Enterprises]
\end{abstract}

\section{Introduction}

Chest physiotherapy is commonly employed in the treatment of infants with respiratory diseases. ${ }^{1}$ Almost all physiotherapy techniques available for infants are derived from adult studies, ${ }^{2-5}$ but the infant respiratory system is differ-

Dr Lanza, Dr Wandalsen, Dr Bianca, Ms Cruz, and Dr Solé are affiliated with the Department of Pediatrics, Federal University of São Paulo, São Paulo, Brazil. Mr Postiaux is affiliated with the Service de Médecine Interne et de Pédiatrie, Grand Hôpital de Charleroi, Charleroi, Belgium.

The authors have disclosed no conflicts of interest.

Correspondence: Fernanda de Cordoba Lanza PT PhD, Department of Pediatrics, Federal University of São Paulo, Estado de Israel Street 465 ap 23, São Paulo, 04022-001 Brazil. E-mail: fernanda_lanza@ hotmail.com.

DOI: $10.4187 /$ respcare. 01067 ent from the adult respiratory system, and the effects of chest physiotherapy may not be the same. ${ }^{6,7}$ New chest physiotherapy techniques were developed specifically for infants, in accordance with their physiological characteristics. ${ }^{8,9}$ Prolonged slow expiration (PSE) is one of these new techniques, employed in clinical practice in infants with bronchial obstruction and hypersecretion..$^{10}$ In PSE, pressure is exerted on the thorax and abdomen to prolong the expiratory phase and thus promote secretion clearance. ${ }^{10,11}$

In infants with viral bronchiolitis, PSE improves respiratory distress, lowers heart rate, and increases $\mathrm{S}_{\mathrm{pO}_{2}}{ }^{10-13} \mathrm{In}$ 2001, some possible benefits of PSE were described, including improved secretion clearance and reduced hyperinflation. ${ }^{12}$ In 2006, Postiaux and co-workers found reduced respiratory distress, lower heart rate, and increased $\mathrm{S}_{\mathrm{pO}_{2}}$ after PSE in 19 infants with viral bronchiolitis. ${ }^{13}$

Although PSE is used in several countries, mainly in Europe, in the 20 years since the first description of PSE 


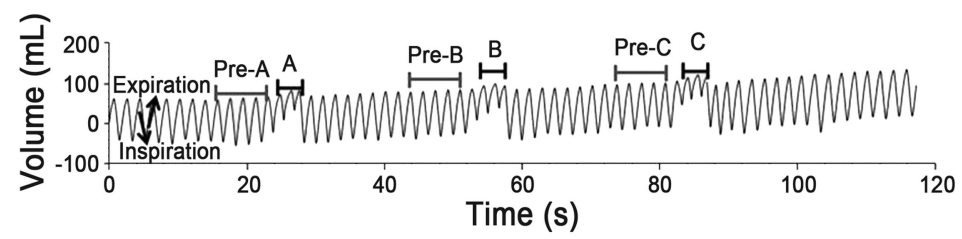

Fig. 1. Example of a volume-time curve during normal breathing and prolonged slow expiration. Pre-A, Pre-B, and Pre-C are the 5 normal breaths before the PSE sequences (A, B, and C).

there has not been a detailed description of PSE in the literature. It is assumed that PSE deflates the lung to expiratory reserve volume (ERV), induces sigh breaths, and does not increase peak expiratory flow (PEF), because it is a slow technique, $, 912,13$ but these assumptions are unproven, and PSE's effects on infant respiratory mechanics are unknown.

Pulmonary function testing in infants allows assessment of pulmonary volumes and capacities, thereby assisting in the determination of disease severity, treatment response, and physiologic changes induced by sigh breaths. ${ }^{14-16}$ This assessment may help physical therapists determine changes in pulmonary function during respiratory therapy techniques such as PSE. In infants with histories of wheezing, we studied PSE's effects on tidal volume $\left(\mathrm{V}_{\mathrm{T}}\right), \mathrm{ERV}, \mathrm{PEF}$, and induction of sigh breaths.

\section{Methods}

This study was approved by the ethics committee of Federal University of São Paulo, São Paulo, Brazil, and performed in the pediatrics department. All the patients' parents gave written, informed consent.

\section{Patients}

We screened all infants referred for pulmonary function testing, and invited full-term babies who had histories of recurrent wheezing (more than 3 wheezing episodes) but no acute respiratory symptoms in the previous 2 weeks. We excluded infants with upper-airway obstruction, symptoms or history of neuropathy, gastroesophageal reflux disease, or thoracic and/or abdominal surgery.

Prior to the pulmonary function testing, the infants had been fasting for a minimum of 3 hours. We administered chloral hydrate $(60-80 \mathrm{mg} / \mathrm{kg})$, per our laboratory routine and the recommendations of the American Thoracic Society/European Respiratory Society. ${ }^{17}$ During the lung function test and the PSE protocol we continuously monitored $\mathrm{S}_{\mathrm{pO}_{2}}$ and heart rate (DX2405, Dixtal, São Paulo, Brazil). The infants were in dorsal decubitus position, with a slight cervical extension created with a small cushion in the scapula region, with no lateralization of the head. We attached a face mask coupled to a pneumotachograph (Hans
Rudolph, Shawnee, Kansas) to the infant's face, and the mask was sealed on the baby's face with a mass to seal the surface and prevent air leakage. The system and face mask's dead space was known and accounted for by the equipment's software. We continuously recorded flow and volume. Each patient had just one set of data collected for analysis. Prior to analyzing the data we checked for the presence of drift in the volume-time curve, from high humidity or temperature.

\section{Prolonged Slow Expiration Protocol}

We first recorded 60 seconds of normal breathing, then conducted the PSE protocol. All PSE procedures were performed by the same therapist (FCL). The therapist positioned the hypothenar region of one hand on the thorax, precisely below the suprasternal notch, and the hypothenar region of the other hand on the abdomen, under the umbilical scar. The therapist visually identified the inspiratory and expiratory phases by observing the thorax movement, and at the end of the expiratory phase applied compression with both hands. The hand on the thorax moved in the cranial-caudal direction while the hand on the abdomen move in the caudal-cranial direction. The subsequent 3 inspirations were restricted, and the compression movements were continued into the expiratory phase, per the standard PSE technique. ${ }^{13,18}$ This procedure was repeated 3 times (sequences $\mathrm{A}, \mathrm{B}$, and $\mathrm{C}$ ), with an interval of 30 seconds between each sequence (Fig. 1).

During both normal breathing and PSE we measured PEF, $\mathrm{V}_{\mathrm{T}}$, and expiration time $\left(\mathrm{T}_{\mathrm{E}}\right)$, and calculated the mean for each sequence (see Fig. 1). We measured the expiratory and inspiratory volume during each PSE manual compression, and we calculated the exhaled $\mathrm{V}_{\mathrm{T}}$ during PSE as the difference between them and expressed the value as a percent of ERV (\%ERV).

Sigh breaths were identified on the flow-volume and volume-time curves, as a $\mathrm{V}_{\mathrm{T}}$ increase of more than $100 \%$. We considered a sigh breath induced by PSE only if it occurred during or just after PSE. We compared the frequency of PSE-induced sigh breath to that during the $60 \mathrm{sec}-$ onds of normal breathing before PSE.

After the PSE protocol we measured ERV with the raisedvolume rapid-thoracic-compression technique, with an in- 
fant pulmonary function testing system (Infant Pulmonary Lab, nSpire Health, Longmont, Colorado) as recommended. ${ }^{15}$ An inflatable jacket is wrapped around the infant's chest and abdomen, and several sequential lung inflations (inspiratory pressure $30 \mathrm{~cm} \mathrm{H}_{2} \mathrm{O}$ ) are delivered to inhibit respiratory effort prior to the thoracic compression. The forced maneuvers are performed by the automated inflation of the jacket, which compresses the chest and maintains expiratory flow until it approaches zero, or for a maximum of 4 seconds. Then we recorded 40 seconds of normal breathing during which we measured the $\mathrm{V}_{\mathrm{T}}$. We calculated ERV as the mean of the difference between the total exhaled $\mathrm{V}_{\mathrm{T}}$ after thoracic compression and the normal $\mathrm{V}_{\mathrm{T}}$, in at least 3 acceptable expiratory curves. ${ }^{15}$

\section{Statistical Analysis}

The sample size calculation to achieve an alpha error of .05 and $90 \%$ power indicated a minimum sample of 14 infants. This was based on a $30 \% \mathrm{~V}_{\mathrm{T}}$ difference between the normal breathing sequence and the PSE sequence observed in a pilot study. All the continuous variables showed normal distribution and are expressed as mean \pm SD.

We considered for analysis the mean values from each PSE sequence (A, B, and C) and each normal-breathing sequence (the 5 respirations prior to each PSE sequence), so we used repeated-measures analysis of variance to compare $\mathrm{V}_{\mathrm{T}}$, PEF, and $\mathrm{T}_{\mathrm{E}}$ between PSE A, PSE B, and PSE C, and to compare $\mathrm{V}_{\mathrm{T}}, \mathrm{PEF}$, and $\mathrm{T}_{\mathrm{E}}$ between normal-breathing sequence $\mathrm{A}$, normal-breathing sequence $\mathrm{B}$, and normal-breathing sequence $\mathrm{C}$.

We also used repeated-measures analysis of variance to compare \%ERV between PSE A, PSE B, and PSE C, and to compare \%ERV within the 3 inspirations in the sequences. For differences with $P \leq .05$ we used a post hoc Bonferroni test.

We compared the number of PSE-induced sigh breaths with the McNemar chi-square test. We calculated the Pearson coefficient to analyze the correlation between \%ERV and age, between \%ERV and the number of wheezing episodes, between age and sigh breaths, and between the number of wheezing episodes and sigh breaths. We used the paired $t$ test to compare the $\mathrm{V}_{\mathrm{T}}, \mathrm{PEF}$, and $\mathrm{T}_{\mathrm{E}}$ values from the normal breathing sequences and the PSE sequences. The level of rejection of the null hypothesis was set at $5 \%$. All analyses were made with statistics software (SPSS 13.0, SPSS, Chicago, Illinois).

\section{Results}

Twenty-two infants were included. Four did not complete the study: one due to cough during the examination, and 3 due to technical difficulties (premature awakening
Table 1. Subjects*

\begin{tabular}{lc}
\hline \hline Female/male & $9 / 9$ \\
Age (weeks) & $32.2 \pm 11.4$ \\
Length $(\mathrm{cm})$ & $68 \pm 4$ \\
Weight $(\mathrm{kg})$ & $8.3 \pm 1.0$ \\
Wheezing episodes, no. & $4.8 \pm 1.9$ \\
Tidal volume (mL/kg) & $9.3 \pm 1.2$ \\
Tidal volume (\% of predicted) & $116 \pm 19$ \\
Respiratory rate (breaths/min) & $40 \pm 7$
\end{tabular}

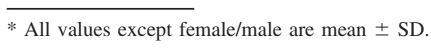

Table 2. Lung Function Variables During Prolonged Slow Expiration Technique*

\begin{tabular}{lrrrr}
\hline \hline & \multicolumn{4}{c}{$\begin{array}{c}\text { Prolonged Slow } \\
\text { Expiration Sequence }\end{array}$} \\
\cline { 2 - 5 } & \multicolumn{1}{c}{ A } & \multicolumn{1}{c}{ B } & C & $P$ \\
\hline Peak expiratory flow (mL/s) & $164 \pm 45$ & $147 \pm 52$ & $147 \pm 47$ & .08 \\
Tidal volume (mL) & $49 \pm 14$ & $43 \pm 18$ & $47 \pm 16$ & .10 \\
Expiratory time (s) & $0.5 \pm 0.2$ & $0.5 \pm 0.1$ & $0.5 \pm 0.1$ & .75 \\
& & & & \\
$*$ Values are mean \pm SD. & & & & \\
\hline
\end{tabular}

Table 3. Lung Function Variables During Normal Breathing*

\begin{tabular}{lrrrr}
\hline \hline & \multicolumn{4}{c}{ Normal Breathing Sequence } \\
\cline { 2 - 4 } & \multicolumn{1}{c}{$\mathrm{A}$} & \multicolumn{1}{c}{$\mathrm{B}$} & \multicolumn{1}{c}{$\mathrm{C}$} & \multirow{2}{*}{$P$} \\
\hline Peak expiratory flow (mL/s) & $149 \pm 32$ & $150 \pm 32$ & $154 \pm 33$ & .54 \\
Tidal volume (mL) & $80 \pm 18$ & $83 \pm 17$ & $83 \pm 17$ & .58 \\
Expiratory time (s) & $0.8 \pm 0.1$ & $0.8 \pm 0.2$ & $0.8 \pm 0.3$ & .60 \\
* Values are mean \pm SD. & & & & \\
\hline
\end{tabular}

and insufficient sedation). Thus, we analyzed the data from 18 infants (Table 1).

The duration of the PSE protocol ranged from 8 to $10 \mathrm{~min}$. During the protocol, none of the infants exhibited signs of respiratory distress, expiratory grunting, or wheezing. During the protocol, in all the infants, $\mathrm{S}_{\mathrm{pO}_{2}}$ remained above $93 \%$, and the heart-rate range was $110-150$ beats $/ \mathrm{min}$.

The mean $\pm \mathrm{SD} \mathrm{V}_{\mathrm{T}}$ was $116 \pm 19 \%$ of predicted. ${ }^{15} \mathrm{PSE}$ flattened the inspiratory and expiratory flow-volume curves. There were no statistically significant changes in PEF, $\mathrm{V}_{\mathrm{T}}$, or $\mathrm{T}_{\mathrm{E}}$ between PSE sequences $\mathrm{A}, \mathrm{B}$, and $\mathrm{C}$ (PEF $P=.08, \mathrm{~V}_{\mathrm{T}} P=.10, \mathrm{~T}_{\mathrm{E}} P=.75$, Table 2) or between the normal breathing sequences (PEF $P=.54$, $\mathrm{V}_{\mathrm{T}} P=.58, \mathrm{~T}_{\mathrm{E}} P=.60$, Table 3 ). Comparing the normal breathing sequences and PSE sequences, there was a mean $\mathrm{V}_{\mathrm{T}}$ reduction of more than $40 \%(P<.001$, Fig. 2) and a consequent $\mathrm{T}_{\mathrm{E}}$ reduction $(P<.001)$. 


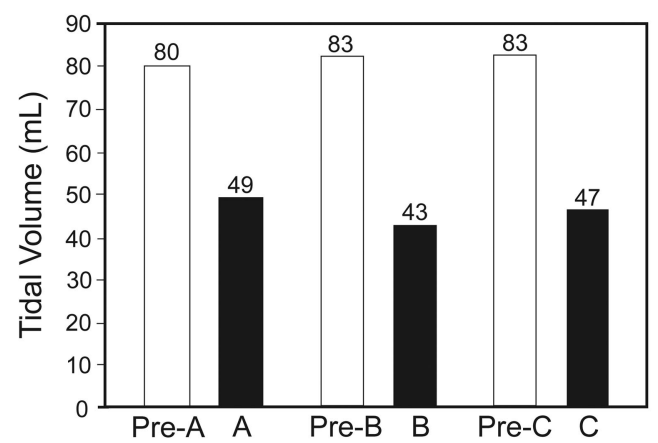

Fig. 2. Tidal volume before (Pre-A, Pre-B, and Pre-C) and during 3 prolonged slow expiration sequences $(\mathrm{A}, \mathrm{B}$, and $\mathrm{C}) . P<.001$ for all 3 differences.

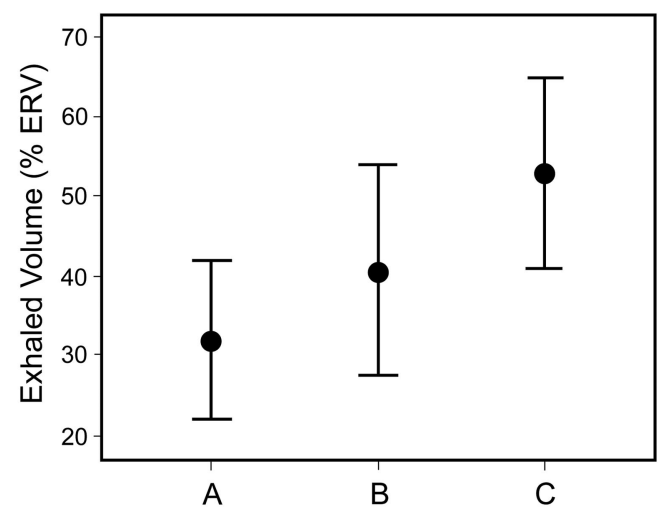

Fig. 3. Exhaled volume in 3 consecutive sequences (A, B, and C) of prolonged slow expiration technique, as a percentage of expiratory reserve volume (\%ERV). $P=.04$ for $A$ versus $B . P<.001$ for $B$ versus $C . P<.001$ for $A$ versus $C$.

PSE-induced sighs were observed in 7 infants significantly more frequently than those observed during normal breathing (1 infant) $(P=.03)$. Each patient sighed only once. In patients who sighed during PSE, the mean \pm SD $\mathrm{V}_{\mathrm{T}}$ increased from $73 \pm 12 \mathrm{~mL}$ to $204 \pm 69 \mathrm{~mL}$, compared to $\mathrm{V}_{\mathrm{T}}$ without versus with sigh breath $(P<.001)$ or $9 \pm 1 \mathrm{~mL} / \mathrm{kg}$ to $26 \pm 8 \mathrm{~mL} / \mathrm{kg}(P<.001)$. The only patient who sighed during normal breathing increased $\mathrm{V}_{\mathrm{T}}$ from $93 \mathrm{~mL}(11 \mathrm{~mL} / \mathrm{kg})$ to $200 \mathrm{~mL}(23 \mathrm{~mL} / \mathrm{kg})$ during the sigh breath. There was no significant correlation between age and the presence of sigh breaths $(\mathrm{r}=-0.27, P=.30)$ or between the number of wheezing episodes and induction of sigh breaths $(\mathrm{r}=-0.32, P=.20)$.

Three of the 18 patients awoke before raised-volume rapid-thoracic-compression, so ERV could be determined in only 15 infants. There was an increase in exhaled volume during the PSE period, in comparison to normal tidal breathing. Progressive exhaled volume quantified as a fraction of ERV was observed in each sequence: the mean
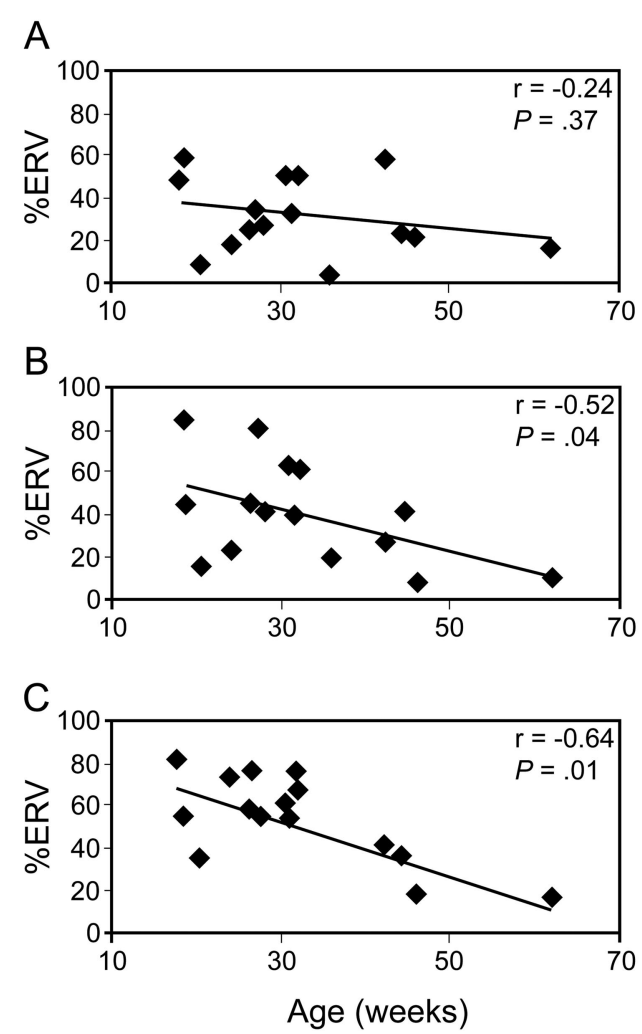

Fig. 4. Correlation between age and exhaled volume (expressed as a percentage of expiratory reserve volume [\%ERV]) in 3 consecutive sequences $(\mathrm{A}, \mathrm{B}$, and $\mathrm{C}$ ) of prolonged slow expiration.

$\%$ ERV was $32 \pm 18 \%$ in sequence $\mathrm{A}, 41 \pm 24 \%$ in sequence $\mathrm{B}$, and $53 \pm 20 \%$ in sequence $\mathrm{C}$ (Fig. 3).

There was a negative correlation between age and \%ERV in sequences $\mathrm{B}$ and $\mathrm{C}(\mathrm{r}=-0.52$ and $\mathrm{r}=-0.64$, respectively, Fig. 4). There was no significant correlation between the number of wheezing episodes and \%ERV $(\mathrm{r}=-0.09, P=.60)$ in any sequences.

There were no significant differences in the variability of exhaled volumes in the PSE sequences. Sequence A varied $17 \pm 10 \mathrm{~mL}$, sequence $\mathrm{B}$ varied $21 \pm 12 \mathrm{~mL}$, and sequence $\mathrm{C}$ varied $20 \pm 13 \mathrm{~mL}$ (all $P>.05$ ).

\section{Discussion}

The benefit of conventional chest physiotherapy in infants remains controversial. ${ }^{19-22}$ Disagreements stem from the use of techniques developed for adults, which do not take into consideration the particularities of the infant respiratory system. New chest physiotherapy techniques especially developed for infants have been employed in recent years. ${ }^{23}$ The existing studies of PSE suggest benefits in infants with hypersecretion or hyperinflation. ${ }^{12,13}$ But a detailed description of PSE's effect on lung volumes and mechanics has been lacking, and is needed as a reference for further PSE studies and improvements. 
The present study demonstrated previously unproven $\mathrm{V}_{\mathrm{T}}, \mathrm{PEF}$, and \%ERV effects of PSE in infants with histories of wheezing. PSE deflated the lung to ERV and induced sigh breaths. Our first observation about the flowvolume curve during PSE was the expressive variation of volume. The $\mathrm{V}_{\mathrm{T}}$ reduction during PSE was approximately $40 \%$ of the baseline volume. This can be explained by the thoracic restriction during the inspiratory phase, which limits the inspired volume in order to prolong the expiratory phase. We did not evaluate mucus clearance, but previous studies found that PSE improved mucus clearance. ${ }^{18,19,24}$ Our supposition is that mucus clearance may be improved by the large variations in $\mathrm{V}_{\mathrm{T}}$, but this theory needs study.

The reduction in lung volume is physiologically associated with the protective reflex of the airways, which restores lung volume by sigh breathing (Hering-Breuer deflation reflex). ${ }^{25}$ In the present study, 7 infants sighed during PSE. We concluded that the prolonged expiratory phase during PSE exhales a substantial portion of the lung volume and thus evokes the Hering-Breuer reflex, indicated by sigh breaths. The Hering-Breuer reflex is more easily induced in younger infants because of the immaturity of their pulmonary receptors, whereas infants with chronic respiratory diseases are less prone to the HeringBreuer reflex, due to pulmonary impairment. ${ }^{26,27}$ In the present study, however, the induction of sigh breaths was not correlated with age or severity of respiratory disease, expressed as number of wheezing episodes. The small age range and the clinical stability of the studied infants, however, do not allow definite conclusions.

It has been presumed that PSE can evoke sigh breaths, but it has not been objectively determined until the present study. Sighing may benefit these patients by improving alveolar ventilation and lung volume. We previously found that sighs can improve forced vital capacity. ${ }^{16}$

After 3 PSE sequences, an average of 53\% of the ERV was exhaled, and there was a $20-25 \%$ increase in exhaled volume after each sequence. This effect was successively greater if more consecutive PSE sequences were applied. An excessive increase in exhaled volume could reduce $\mathrm{S}_{\mathrm{pO}_{2}}$ and lead to respiratory distress caused by bronchial collapse, which may occur when residual volume is reached. Thus, the experience and training of the physiotherapist are essential, so that PSE is applied without placing the infant at risk. After 3 PSE sequences we observed a mean exhalation of $52 \%$ of ERV, which is certainly a safe percentage of the lung volume.

We know of no previous studies that calculated \%ERV in spontaneously breathing infants during PSE. Studies in adults with chronic pulmonary disease have described a reduction in final expiratory volume after physiotherapy techniques that actively promote a prolonged expiratory phase, as does PSE. 28,29
We observed a statistically significant inverse correlation between age and \%ERV. There was a greater exhaled volume among the younger infants, and this may be explained by the greater compliance of the thoracic cage in these infants, ${ }^{30}$ which suggests that PSE may be more effective in younger infants. Fewer sequences of manual compression may be needed in these younger infants. The physiotherapist must be alert for the risk of respiratory distress if many PSE sequences are applied consecutively.

The fact that there was no significant correlation between \%ERV and the number of wheezing episodes indicates that the effectiveness of the exhalation volume was not associated with the severity of the illness in this group. However, further studies are needed to corroborate this finding in different diseases and in different severities.

PSE was described as a slow technique that does not increase airway flow. ${ }^{18} \mathrm{We}$ confirmed this hypothesis in our study. Postiaux and collaborators assessed PSE in infants with respiratory illness, by monitoring flow curves, and also found no change in expiratory flow. ${ }^{24}$ Rapidcompression physiotherapy techniques are not indicated in infants because of thorax instability. ${ }^{1,31}$

Manual physiotherapy techniques are always dependent on the ability and practice of the physical therapist, and are susceptible to practice differences and variation..$^{32,33}$ In the present study all the PSE sequences were applied by the same physiotherapist, and we found no important practice variation in the PSE sequences. Research is needed on PSE practice variation between compressions and between physiotherapists. A study of other physiotherapy techniques in adults found minimal variability when manual chest physiotherapy was performed by a trained physiotherapist. ${ }^{34}$

We did not observe any wheezing exacerbations during the PSE protocol. We chose infants with histories of wheezing so as to study patients similar to those on whom PSE is usually performed. Unfortunately, safety reasons limit the feasibility of sedation and lung function test in infants with acute wheezing or respiratory distress. Chloral hydrate at doses of $60-80 \mathrm{mg} / \mathrm{kg}$ is described as safe and with minimal alterations in gasometrical and pulmonary variables such as respiratory-system compliance, respiratory drive, and lung volumes. ${ }^{17,35-37}$ In a sedated infant, PSE could minimally interfere with respiratory variables, and during clinical practice it is not rare to treat sedated patients. We believe that the chloral hydrate did not affect these variables during our study.

\section{Conclusions}

Our results confirm previous assumptions about PSE in infants. $V_{T}$ was reduced during PSE. PEF was maintained as expected in slow techniques. PSE promoted sigh breaths, thereby demonstrating that the change in volume caused by PSE stimulates the Hering-Breuer deflation reflex. An- 
other important finding was that PSE deflates the lung to ERV. Now we know that it is possible to reach the fraction of ERV with PSE. Thus, \%ERV exhaled is greater, increasing the number of successive PSE sequences (cumulative effect). Age was negatively correlated with the \%ERV changes, so we must be careful with younger infants, whereas the severity of the illness did not affect \%ERV. We found no important PSE technique variability in the one physiotherapist who performed all the PSE sequences.

\section{REFERENCES}

1. Oberwaldner B. Physiotherapy airway clearance in pediatrics. Eur Respir J 2000;15(1):195-204.

2. Zach MS, Oberdwaldner B. Chest physiotherapy: the mechanical approach to antiinfective therapy in cystic fibrosis. Infection 1987; 15(5):381-384.

3. Mellins RB. Pulmonary physiotherapy in the pediatric age group. Am Rev Respir Dis 1974;110(6 Pt 2):137-142.

4. Krause MF, Hoehn T. Chest physiotherapy in mechanically ventilated children: a review. Crit Care Med 2000;28(5):1648-1651.

5. Hess DR. Airway clearance: physiology, pharmacology, techniques, and practice. Respir Care 2007;52(10):1392-1396.

6. Perrotta C, Ortiz Z, Roqué FM. Chest physiotherapy for acute bronchiolitis in pediatric patients between 0 and 24 months old. Cochrane Database Syst Rev 2007;(1):CD004873.

7. Prasad SA, Main E, Dodd ME. Finding consensus on the physiotherapy management of asymptomatic infants with cystic fibrosis. Pediatr Pulmonol 2008;43(3):236-244.

8. Fox W, Schwartz JG, Shaffer TH. Pulmonary physiotherapy in neonates: physiologic changes and respiratory management. J Pediatr 1978;92(6):977-981.

9. Almeida CCB, Ribeiro JD, Almeida-Junior AA, Zeferino AMB. Effect of expiratory flow increase technique on pulmonary function of infants on mechanical ventilation. Physiother Respir Int 2005;10(4):213-221.

10. Postiaux G, Bafico JF, Masengu R, Lahaye JM. Paramètres anamnestiques et cliniques utiles au suivi et à l'achèvement de la toilette bronchopulmonaire du nourrisson et de l'enfant. Ann Kinésithér 1991; 18(3):117-124. Article in French.

11. van der Schans CP. Forced manoeuvers to increase transport of bronchial mucus: a mechanistic approach. Monaldi Arch Chest Dis 1997;52(4):367-370.

12. Postiaux G. Quelles sont les techniques de desencombrement bronchique et des voies aériennes supérieures adaptées chez le nourrisson? Arch Pédiatr 2001;8(Suppl 1):117S-125S. Article in French.

13. Postiaux G, Dubois R, Marchand E, Demay M, Jacquy J, Mangiaracina $M$. Effets de la kinésithérapie respiratoire associant expiration lente prolongée et toux provoquée dans la bronchiolite du nourrisson. Kinesither Rev 2006;6(55):35-41. Article in French.

14. Jones M, Castile R, Davis S, Kisling J, Filbrun D, Flucke R, et al. Forced expiratory flows and volumes in infants normative data and lung growth. Am J Respir Crit Care Med 2000;161(2):353-359.

15. American Thoracic Society (ATS)/European Respiratory Society (ERS) Statement. Raised volume forced expirations in infants: recommendations for current practice. Am J Respir Crit Care Med 2005;172(11):1463-1471.

16. Wandalsen GF, La Scala CS, Lanza F, Molero JC Jr, Solé D. Influence of sighs in the raised volume rapid thoracic compression technique (RVRTC) in infants. Pediatr Pulmonol 2008;43(4):360-365.
17. Gaultier C, Fletcher ME, Beardsmore C, England S, Motoyama E; ATS/ERS working group on standardization of infant pulmonary function tests. Respiratory function measurements in infants: measurement conditions. Eur Respir J 1995;8(7):1057-1066.

18. Postiaux G. Des techniques expiratoires lentes pour l'épuration des voies aériennes distales. Ann Kinésithér 1997;24(4):166-177. Article in French.

19. Webb MS, Martin JA, Cartilidge PH, King Y, Wright NA. Chest physiotherapy in acute bronchiolitis. Arch Dis Child 1985;60(11): 1078-1090.

20. Harding JE, Miles FKI, Becroft DMO, Allen BC, Knight DB. Chest physiotherapy may be associated with brain damage in extremely premature infants. J Pediatr 1998;132(3Pt 1):440-444.

21. Ribeiro MA, Cunha ML, Etchebehere EC, Camargo EE, Ribeiro JD, Condino-Neto A. Efeito da cisaprida e da chest physiotherapy sobre o refluxo gastroesofágico de lactentes chiadores segundo avaliação cintilográfica. J Pediatr (Rio J) 2001;77(5):393-400. Article in Portuguese.

22. Hess DR. Secretion clearance techniques: absence of proof or proof of absence? Respir Care 2002;47(7):757-759.

23. Proceedings 1 ére Conferénce de Consensus en kinésithérapie respiratoire. Lyon 1994. Kinesith Scient 1995;334(11):45-54. Article in French.

24. Postiaux G, Ladha K, Gillard C, Charlier JL, Lens E. La kinésithérapie respiratoire du tout-petit $<24$ mois guidée par l'auscultation pulmonaire. Rev Fr Allergol 1997;37(2):206-2012. Article in French.

25. Rabbette PS, Stocks J. Influence of volume dependency and timing of airway occlusions on the Hering-Breuer reflex in infants. J Appl Physiol 1998;85(6):2033-2039.

26. Rabbette PS, Costeloe KL, Stocks J. Persistence of the Hering-Breuer reflex beyond the neonatal period. J Appl Physiol 1991;71(2):474-480.

27. Clark FJ, von Euler C. On the regulation of depth and rate of breathing. J Physiol Lond 1972;222(2):267-295.

28. Bianchi R, Gigliotti F, Romagnoli I, Lanini B, Castellani C, Grazzini M, Scano G. Chest wall kinematics and breathlessness during pursedlip breathing in patients with COPD. Chest 2004;125(2):459-465.

29. Spahija J, Marchie M, Grassino A. Effects of imposed pursed-lips breathing on respiratory mechanics and dyspnea at rest and during exercise in COPD. Chest 2005;128(2):640-650.

30. Schechter MS. Airway clearance applications in infants and children. Respir Care 2007;52(10):1382-1391.

31. Wils J. L'accélérat ion du flux expirat oire chez l'adulte: technique de désencombrement bronchique. Cah Kinésithér 1998;192(4):1-13. Article in French.

32. Blazey S, Jenkins S, Smith R. Rate and force of application of manual chest percussion by physiotherapists. Aust J Physiother 1998; 44(4):257-264.

33. Wong WP, Paratz D, Wilson K, Burns YR. Hemodynamic and ventilatory effects of manual respiratory physiotherapy techniques of chest clapping, vibration, and shaking in an animal model. J Appl Physiol 2003;95(3):991-998.

34. Shannon H, Gregson R, Stocks J, Cole TJ, Main E. Repeatability of physiotherapy chest wall vibrations applied to spontaneously breathing adults. Physiotherapy 2009;95(1):36-42.

35. Jackson EA, Rabbete PS, Dezateux C, Hatch DJ, Stocks J. The effect of triclofos sodium sedation on respiratory rate, oxygen saturation and heart rate in infants and young children. Pediatr Pulmonol 1991; 10(1):40-45.

36. Rabbette PS, Dezateux CA, Fletcher ME, Costeloe KL, Stocks J. Influence of sedation on the Hering-Breuer inflation reflex in healthy infants. Pediatr Pulmonol 1991;11(3):217-222.

37. Mallol J, Sly PD. Effect of chloral hydrate on arterial oxygen saturation in wheezy infants. Pediatr Pulmonol 1988;5(2):96-99. 